\title{
RHINOLOGY
}

\section{Implementing strategies for data collection in chronic rhinosinusitis}

\author{
Strategie integrative nella raccolta dati del paziente affetto da rinosinusite cronica \\ P. CASTELNUOVO ${ }^{12}$, F. BANDI ${ }^{1}$, A. PRETI ${ }^{23}$, E. SICA ${ }^{1}$, F. DE BERNARDI ${ }^{1}$, S. GALLO ${ }^{12}$ \\ ${ }^{1}$ Department of Otorhinolaryngology, University of Insubria and ASST Sette Laghi, Ospedale di Circolo, Varese, \\ Italy; ${ }^{2}$ Department of Biotechnology and Life Sciences (DBSV), University of Insubria, Varese, Italy; ${ }^{3}$ Department of \\ Otorhinolaryngology, University of Milan and IRCCS Multimedica, Ospedale San Giuseppe, Milan, Italy
}

\begin{abstract}
SUMMARY
Chronic rhinosinusitis (CRS) is a debated topic in the international rhinologic literature because of its high prevalence, heterogeneity of clinical manifestations and unpredictability of disease course. Recently, the focus in CRS research has moved to identify biological subtypes that might explain its aetiology and clinical variability. However, these analyses are still expensive and limited to scientific purposes, so that they cannot be used on a large scale in daily practice. For this reason, we wondered if it was possible to define a risk stratification for CRS patients based only on first level investigations. The heterogeneity of the disease has given us a large amount of data compelling to find an additional storage system. Herein, we present the results of our work, the RhinoBank, as we believe that it is an easy-to-use tool for those professionals dealing with CRS and an effective system to exploit in clinical research.
\end{abstract}

KEY WORDS: Chronic rhinosinusitis $\bullet$ Phenotypes $\bullet$ Endotypes $\bullet$ Database $\bullet$ Clinical trials

\section{RIASSUNTO}

La rinosinusite cronica (CRS) rappresenta un argomento dibattuto nella letteratura rinologica internazionale a causa della sua alta prevalenza, dell'eterogeneità delle manifestazioni cliniche e della difficoltà a predire l'andamento della malattia. Recentemente l'attenzione della ricerca nella CRS si è spostata verso l'identificazione di sottotipi biologici che possano giustificare l'eziologia e la variabilità clinica. Tuttavia, queste analisi risultano ancora costose e limitate nell'impiego per scopi di ricerca, per cui non applicabili su larga scala e nella pratica clinica quotidiana. Per questo motivo ci siamo domandati se fosse possibile ottenere una stratificazione del paziente rinosinusitico solo sulla base di indagini di primo livello. L'eterogeneità intrinseca della malattia ci ha messo di fronte ad una vasta quantità di dati obbligandoci a trovare strategie di archiviazione addizionali. Presentiamo quindi il frutto del nostro lavoro, il RhinoBank, principalmente per due motivi. Crediamo che sia uno strumento di facile impiego a disposizione di chiunque tratti questa patologia ed un sistema efficace da sfruttare nella ricerca clinica.

PAROLE CHIAVE: Rinosinusite cronica $\bullet$ Fenotipi $\bullet$ Endotipi $\bullet$ Banche dati $\bullet$ Studi clinici

Acta Otorhinolaryngol Ital 2018;38:222-224

Chronic rhinosinusitis (CRS) is a frequent disease. Its true prevalence is challenging to be accurately estimated because it depends on the epidemiological methodology employed. However, according to studies based on largescale questionnaires, it ranges from around 10 to $12 \%$ in Europe and the US. Moreover, CRS represents a burden both to individuals and society ${ }^{1}$.

In recent years, with the demand to justify therapeutic failures, the scientific community has began to critically review the diagnostic criteria for CRS and realised that they were not sufficient to explain the heterogeneity of the disease. There is, in fact, a broad spectrum of rhi- nosinusitis manifestations, ranging from simple paranasal sinus dysventilation to frank nasal polyposis, which is not adequately taken into account by the phenotypic classification based on guidelines. The classic dichotomy between CRS with nasal polyps (CRSwNP) and CRS without nasal polyps (CRSsNP) is too simplistic to explain a disorder that is actually considered as a complex multifactorial disease grounded on the interplay between gene-susceptibility and the exposome (microbiota, immunity, epigenetics, nutrition) ${ }^{2-4}$.

In the attempt to overcome this limit, we gradually shifted to a different perspective for which the clinical phenotype 
is in reality nothing but the emerging part of a massive iceberg.

All these considerations were inherited from the pulmonology field. Studies on asthma endotyping have been mentioned since 2008, when the literature began to put a new focus on pathogenetic mechanisms, recognising the complexity and variability of chronic inflammatory disorders of the airways ${ }^{5}$. All these efforts have been made to correlate the clinical phenotype to the course of the disease and its response to therapies ${ }^{6}$. In 2013, the concept of endotyping in CRS first appeared ${ }^{7}$. This consensus is the expression of the consciousness that CRS heterogeneity is supported by multiple biological subtypes (endotypes), each of which is defined by a distinct pathophysiological mechanism, determined equally by a well-defined genetic-environmental interaction. Each endotype should be in a theoretical line identified by a biomarker, to be intended both as diagnostic marker and as prognostic and therapeutic indicator. To find a highly predictive biomarker, a long series of key requirements for reproducibility, accessibility and stability must be met. In truth, we are still facing with the lack of an ideal biomarker that identifies CRS endotypes, allows a precise estimation of the severity of inflammation and predicts possible therapeutic responses. Therefore, it is likely that only a combination of biomarkers will be adequate to characterise each specific CRS subtype $^{8}$.

It is intrinsic to the concept of a multifactorial disease, as CRS, the existence not only of multiple predisposing factors (risk factors), but also of other concomitant pathological conditions (pre and comorbidities) that contribute in shaping the phenotype. Differentiation of pre- and comorbid and risk factors is not easy, because of the variability in disease definitions, the lack of longitudinal studies that establish temporal relationship between exposure and disease onset and the difficulty of assessing the dose-effect size on disease severity.

Furthermore, the opportunity to attest the effectiveness of "standard" therapies is limited by the wide variability of treatment types, patient selection and outcome assessments.

A non-negligible number of prior studies, which reported high proportions of patients improving following medical and/or surgical treatments, were, however, retrospective analyses, which deduced subjective parameters or collected results though unverified surveys ${ }^{9}$. There was no standard for categorising preoperative status, extent of disease or surgical outcomes, and many of these studies were unable to interpret the clinical relevance of a specific treatment or further delineate subgroups of patients who did or did not experience improvement. In addition, single institution studies have been criticised for the potential lack of generalisability to patients population, an issue at least partially addressed by incorporating a multi-institutional study design ${ }^{10}{ }^{11}$. In the last years, the introduction of validated disease-specific quality of life (QoL) and general health-related QoL outcomes instruments allowed building a standard assessment of CRS patients.

Notwithstanding, in our opinion, the exclusive evaluation of outcomes based on symptomatic and objective scores (endoscopic, radiological) may be limitative. A previous prospective-designed publication showed that other clinical factors (such as asthma, ASA intolerance, prior sinus surgery etc.) were found to be important predictors of outcomes ${ }^{10}$. Our idea is that patients affected by CRS should be framed as a whole, going beyond a sole rhinological point of view in a multidisciplinary perspective ${ }^{12}$.

Consequently, a very frequent disease associated with multiple variables generates a large amount of data that should be collected. It clearly emerges that there is a need to establish a systematic approach for data collection and evaluation of outcomes.

Our tertiary care institution is working toward this direction and has created a CRS online database, called RhinoBank. Its advantages are many. First of all, it allows storing data in a single solution with the possibility of easily retrieving previously stored data. In addition, it provides the physician all the information at a glance, allowing location of missing data in a very simple way. Lastly, it enables data sharing with other work centres.

The aim of this letter is to present the efforts of our work in search of active collaboration. We are aware that the database can be further upgraded thanks to suggestions or implementations from other experts in the field. The database now contains only basic clinical information that can be routinely obtained in any hospital. It is not envisaged to store third level parameters such as genetic or biomolecular markers. This will be the next step, dictated by the possibility to perform a more detailed analysis in our institute.

The proposal is to spread this data collection system to other national centres to obtain large and uniform cohorts of patients. The goal is to overcome that lack of constant parameters, that is a critical element inside systematic reviews that hinders the possibility to draw conclusions on clinical practice ${ }^{9}$. The database is at disposal for consultation at: https://www.rhinobank.eu/demo/admLoginWin.asp. (Account access: Username, Admin; Password, demo000.)

\section{Acknowledgements}

The authors are grateful to Massimo Di Marco, senior 
software developer, for supporting them in the technical building process of the RhinoBank. Stefania Gallo is a PhD student of the "Biotechnology, Biosciences and Surgical Technology" course at Università degli studi of Insubria. Andrea Preti is a PhD student of the "Sperimental and translational medicine" course at Università degli studi of Insubria.

\section{References}

1 Bachert C, Zhang L, Gevaert P. Current and future treatment options for adult chronic rhinosinusitis: focus on nasal polyposis. J Allergy Clin Immunol 2015;136:1431-40.

2 Tomassen P, Vandeplas G, Van Zele T, et al. Inflammatory endotypes of chronic rhinosinusitis based on cluster analysis of biomarkers. J Allergy Clin Immunol 2016;137:1449-56.

3 Divekar R, Rank M, Squillace D, et al. Unsupervised network mapping of commercially available immunoassay yields three distinct chronic rhinosinusitis endotypes. Int Forum Allergy Rhinol 2017;7:373-9.

4 Adnane C, Adouly T, Khallouk A et al. Using preoperative unsupervised cluster analysis of chronic rhinosinusitis to inform patient decision and endoscopic sinus surgery outcome. Eur Arch Otorhinolaryngol 2017;274:879-85.

5 Anderson GP. Endotyping asthma: new insights into key pathogenic mechanisms in a complex, heterogeneous disease. Lancet 2008;372:1107-19.

6 Agache I, Akdis C, Jutel M, et al. Untangling asthma phenotypes and endotypes. Allergy 2012;67:835-46.

7 Akdis CA, Bachert C, Cingi C, et al. Endotypes and phenotypes of chronic rhinosinusitis: a PRACTALL document of the European Academy of Allergy and Clinical Immunology and the American Academy of Allergy, Asthma \& Immunology. J Allergy Clin Immunol 2013;131:1479-90.

8 Bachert C, Akdis CA. Phenotypes and emerging endotypes of chronic rhinosinusitis. J Allergy Clin Immunol Pract 2016;4:621-8.

9 Rimmer J, Fokkens W, Chong LY, et al. Surgical versus medical interventions for chronic rhinosinusitis with nasal polyps. Cochrane Database Syst Rev 2014;(12):CD006991.

10 Smith TL, Litvack JR, Hwang PH, et al. Determinants of outcomes of sinus surgery: a multi-institutional prospective cohort study. Otolaryngol Head Neck Surg 2010;142:55-63.

11 Fadda GL, Berrone M, Crosetti E, et al. Monolateral sinonasal complications of dental disease or treatment: when does endoscopic endonasal surgery require an intraoral approach? Acta Otorhinolaryngol Ital 2016;36:300-9.

12 Gelardi M, Iannuzzi L, De Giosa M, et al. Non-surgical management of chronic rhinosinusitis with nasal polyps based on clinical-cytological grading: a precision medicine-based approach. Acta Otorhinolaryngol Ital 2017;37:38-45. 